\title{
Effect of peppermint and thyme essential oil mist on performance and physiological parameters in broiler chickens
}

\author{
D. Witkowska ${ }^{1 \#}$, J. Sowińska ${ }^{1}$, D. Murawska², P. Matusevičius ${ }^{3}$, A. Kwiatkowska-Stenzel ${ }^{1}$, \\ T. Mituniewicz ${ }^{1}$ \& A. Wójcik ${ }^{1}$ \\ ${ }^{1}$ Department of Animal and Environmental Hygiene, Faculty of Animal Bioengineering, University of Warmia and Mazury, \\ Olsztyn, Poland \\ ${ }^{2}$ Department of Commodity Science and Animal Improvement, Faculty of Animal Bioengineering, University of Warmia \\ and Mazury, Olsztyn, Poland \\ ${ }^{3}$ Department of Animal Breeding and Nutrition, Faculty of Animal Husbandry Technology, Lithuanian University of Health \\ Sciences, Kaunas, Lithuania
}

(Received 24 July 2018; Accepted 13 November 2018; First published online 2 March 2019)

\author{
Copyright resides with the authors in terms of the Creative Commons Attribution 4.0 South African Licence. \\ See: http://creativecommons.org/licenses/by/4.0/za \\ Condition of use: The user may copy, distribute, transmit and adapt the work, but must recognise the authors and the South \\ African Journal of Animal Science.
}

\begin{abstract}
The aim of this study was to determine the effect of peppermint and thyme essential oil mist on performance, blood parameters and lymphoid organ indices in broiler chickens. The experiment was conducted on 360 broilers raised until 42 days of age. One-day-old chicks were divided into three groups $(n=120)$ : control group ( $C$ - misted with pure water) and two experimental groups (PO - misted with peppermint essential oil, and TO-misted with thyme essential oil) and placed in three separate experimental rooms. Growth performance (BW - body weight, WG - weight gain, FCR - feed conversion ratio), blood parameters (RBC - red blood cells, HGB - haemoglobin concentration, HCT - haematocrit levels, leukogram, serum protein and protein fractions), and lymphoid organ indices were assessed during the production cycle. Our results demonstrate that the use of EO mist does not exert adverse effects on broiler health, and that PO mist can increase BW and WG in broiler chickens. Mean RBC parameters at slaughter were higher in broilers exposed to PO mist. An analysis of blood parameters and lymphoid organ indices revealed that EO could positively influence the immune systems of birds. Higher values of gammaglobulin concentration as well as the weights and growth indices of lymphoid organs were noted in experimental groups.
\end{abstract}

Keywords: Blood parameters, broilers, essential oils, lymphoid organs, performance

\#Corresponding author: dorota.witkowska@uwm.edu.pl

\section{Introduction}

Essential oils (EO) have long been known to possess immunostimulatory, anti-inflammatory, antioxidant and antimicrobial properties (Kalemba, 1998; Lutomski \& Kędzia, 2000; Krishan \& Narang, 2014; Placha et al., 2014). In human medicine, EO administered orally or as vapour inhalation contribute to the treatment of respiratory problems such as bronchitis, asthma and chronic obstructive pulmonary disease (Juergens et al., 2003; Mitch et al., 2004; Sadlon \& Lamson, 2010).

In a study evaluating the anti-inflammatory and immunostimulatory effects of EO and their components administered per os to mice and rats, Lutomski \& Kędzia (2000) reported the highest levels of anti-inflammatory activity in thyme, sage, peppermint, 1,8-cineol, juniper, and eucalyptus EO. Thyme oil exhibited higher levels of anti-inflammatory activity than a referenced anti-inflammatory drug (indomethacin). Thyme oil was also one of the most potent immunostimulants in the cited study.

In poultry production, vaccination failure, immunosuppressive diseases, and overuse of antibiotics can induce immunodeficiency, which is why immunostimulators should be used in poultry farms to prevent infectious diseases (Hashemipour et al., 2013). Arab-Ameri et al. (2016) demonstrated that the addition of peppermint powder, a potent antioxidant, to feed improved immunity and minimized oxidative stress in heatstressed broilers. Animal feed is widely supplemented with EO as an alternative to antibiotic growth 
promoters, which have been banned in the European Union due to growing levels of antimicrobial resistance (Brenesa \& Rourab, 2010; Hashemipour et al., 2013; Krishan \& Narang, 2014; Gazanfari et al., 2015; Darabighane et al., 2017). The beneficial effects of herbal preparations and EO, including thyme and peppermint oil, on the performance of broiler chickens have been described by many researchers (Hernàndez et al., 2004; Cross et al., 2007; Ocak et al., 2008; Brenesa \& Rourab, 2010; Tiihonen et al., 2010; Bento et al., 2013; Hashemipour et al., 2013; Awaad et al., 2016; Ahmed et al., 2016; Pournazari et al., 2017; Wade et al., 2018). In the work of Toghyani et al. (2010b), the supplementation of broilers diets with thyme improved broiler performance to a similar extent as antibiotic growth promoters, but without exerting effects on immune responses or blood parameters. In contrast, other authors reported that the addition of peppermint and eucalyptus EO to broiler diets led to the activation of the bursa of Fabricius (BF), thymus and spleen. The oil blend also exerted immunomodulatory effects on and increased immunity against the viscerotropic velogenic Newcastle disease (VVND) virus which causes substantial losses in poultry production. Peppermint and eucalyptus EO also improved clinical and pathological parameters (Awaad et al., 2010; Awaad et al., 2016). Hashemipour et al. (2013) demonstrated that feed supplementation with thymol and carvacrol, the main terpene compounds in thyme oil, improved the immune status of broilers.

Despite these findings, the influence of EO on the immune status and health of chickens has not been widely investigated (Abudabos \& Alyemni, 2013; Hashemipour et al., 2013). According to some authors, diets with higher inclusion levels of selected EO compounds had toxic effects (Krishan \& Narang, 2014). In an in vitro study of mammalian cell cultures, Inouye et al. (2003) demonstrated that selected oils may be cytotoxic. In view of the findings articulated above, further research is needed to determine the effects of EO on live birds.

Commercial products containing EO, including peppermint oil, can be administered to birds via their drinking water or used in the fumigation of poultry houses to stimulate the birds' respiratory and immune systems. Despite the above, the effects of EO mist on the growth performance and immune status of poultry have not been thoroughly investigated to date. The effectiveness of inhalation treatments involving EO mist remains unknown. Essential oils administered as mist could be more effective because they contain a mixture of highly volatile aroma compounds. For this reason, essential oils are also known as ethereal oils. Inhalation therapy is recommended for lung diseases such as asthma, cystic fibrosis and chronic obstructive pulmonary disease because it targets specific organs; it can be administered at lower doses than oral or intramuscular treatments, and it has less severe adverse effects (Rau, 2005; Ibrahim et al., 2015). Localised therapies involve smaller doses of the active ingredients, and minimize systemic side effects (Ibrahim et al., 2015).

Due to its antimicrobial properties, EO mist also improves hygiene standards on broiler farms (Bakutis et al., 2011; Witkowska \& Sowińska, 2013; Witkowska et al., 2016). A reduction in microbial contamination levels at the source of the infection can indirectly improve performance and blood parameters in broilers (Witkowska et al., 2007; Mituniewicz et al., 2008; Witkowska \& Sowińska, 2017).

Therefore, the aim of this study was to determine the effect of peppermint and thyme essential oil mist on growth performance, blood parameters and lymphoid organ indices in broiler chickens.

\section{Materials and Methods}

The experimental procedures were approved by the Local Ethics Committee for Animal Experimentation at the University of Warmia and Mazury in Olsztyn (Resolution No. 70/2010).

The experiment was conducted on unsexed 360 Ross 308 broiler chickens raised until 42 days of age. One-day-old chicks were divided into three groups (120 birds in each group): one control group (C - misted with pure water) and two experimental groups (PO - misted with peppermint essential oil, and TO - misted with thyme essential oil). Each group (C, PO and TO) was placed in the same experimental building in three separate rooms, i.e., each treatment was performed in a separate room. Birds were housed in accordance with standard welfare requirements, on straw litter, in identical rooms equipped with mechanical ventilation and lighting. Initial ambient temperature was around $30^{\circ} \mathrm{C}$, and it was gradually decreased to $20^{\circ} \mathrm{C}$ at the end of rearing. Relative humidity ranged from $40 \%$ to $70 \%$. Stocking density in each compartment was 22 $\mathrm{kg} / \mathrm{m}^{2}$ before slaughter. Broilers were fed ad libitum a complete commercial diet (Rolpol, Uścikowo, Poland). Chicks in the hatchery were vaccinated against infectious bronchitis, infectious bursal disease, Marek's disease and Newcastle disease.

Commercial 100\% natural oils (ETJA Corp., Elblagg, Poland) were misted in chicken houses before the experiment and every third day during the experiment. The experimental premises were fogged with $0.5 \mathrm{~L}$ of an aqueous mixture of peppermint essential oil from Mentha piperita and thyme essential oil from Thymus vulgaris L. Essential oils were emulsified in $0.5 \%$ Tween 20 and mixed with hot water in doses suggested by the producer for human aerosol therapy (based on the cubic capacity of fogged compartments). The EO to water ratio was $1: 500$ in the first two weeks of the study, and it was increased to $1: 250$ in the third week 
until slaughter. Control group premises were fogged with $0.5 \mathrm{~L}$ of pure water. Essential oils were dispensed with the Mgła-E diffuser (Poltech Corp., Warsaw, Poland) which generates aerosol particles smaller than 50 $\mu \mathrm{m}$.

Final body weight (BW), weight gain (WG) and feed conversion ratio (FCR) were assessed in all birds. At the end of the experiment, sexing based on visual examination revealed that the ratio of males to females was equal in each group. Mortality rates were also recorded.

On days 28, 35 and 42, 16 birds (eight males and eight females) with BW close to the average of each group were selected and blood samples were collected from the brachial vein for analyses. Red blood cell parameters, including red blood cell counts (RBC), haemoglobin concentration (HGB), and haematocrit levels (HTC), as well as leukogram parameters were determined according to standard procedures (Clark et al., 2009). Serum samples were analysed for total protein content and the content of C-reactive protein (CRP) using the Hitachi 912 analyser (Roche Corp., Germany). Serum protein fractions were determined by electrophoresis on agarose gel in a diagnostic chamber with the DS-2 densitometer (Cormay Group, Poland).

At the end of every experimental week (weeks 1 to 6), eight broiler chickens from each group (four males and four females) whose BW were close to the group average were sacrificed. The thymus, spleen, and bursa of Fabricius were collected from all sacrificed birds and weighed. Immune organ parameters were calculated according to the following formula:

organ weight index $=($ organ weight $/$ body weight $) \times 1000$

The effects of one experimental factor (treatment) was analysed at three levels (C, PO, and TO). At each level, birds were treated individually. The results obtained in all stages of the experiment were analysed separately by one-way ANOVA in the Statistica 12 program (StatSoft Inc., Tulsa, OK). Mean values were compared by Duncan's multiple range test at significance levels of $P<0.001, P<0.01$ and $P<0.05$.

\section{Results}

The effects of PO and TO mist on final BW, WG and FCR in broiler chickens are shown in Table 1.

Table 1 Effects of essential oil mist on the growth performance in broiler chickens (mean values ${ }^{1}$, SEM)

\begin{tabular}{lcccccc}
\hline Parameter & Day/Period & Control & Peppermint oil & Thyme oil & SEM & $P$-value \\
\hline FBW $^{2}(\mathrm{~g})$ & 42 & $2602.62^{\mathrm{B}}$ & $2696.61^{\mathrm{A}}$ & $2549.17^{\mathrm{B}}$ & 37.839 & 0.008 \\
WG $(\mathrm{g})$ & $1-42$ & $2559.07^{\mathrm{B}}$ & $2653.13^{\mathrm{A}}$ & $2.505 .56^{\mathrm{B}}$ & 35.295 & 0.006 \\
FCR $(\mathrm{g} / \mathrm{g})$ & $1-42$ & 1.67 & 1.64 & 1.72 & 0.117 & $\mathrm{NS}^{1}$ \\
Mortality (\%) & $1-42$ & 1.66 & 1.66 & 1.66 & - & - \\
\hline
\end{tabular}

\footnotetext{
${ }^{A-B}$ Mean values within a row having different superscripts differ at level of $P<0.01$

${ }^{1} \mathrm{NS}-P>0.05$

${ }^{2}$ FBW - final body weight; WG - weight gain; FCR - feed conversion ratio
}

During the entire experiment, mean BW and WG were higher in broiler chickens exposed to PO mist than in control birds and chickens exposed to TO mist. In group PO, the highest increase in BW and WG was determined at slaughter $(P<0.01)$. Chickens exposed to TO mist were characterised by lower final BW and WG than birds exposed to PO mist $(P<0.01)$, whereas similar values were noted in group $C(P>0.05)$. Average FCR did not differ $(P>0.05)$ across groups throughout the experiment (days 1 - 42). However, birds exposed to TO mist were characterised by the highest FCR $(P>0.05)$, particularly at the last stage of the experiment.

The mean values of RBC parameters in experimental broilers on days 28,35 and 42 are presented in Table 2. No significant differences were observed between groups on days 28 and 35 . A significant increase in RBC counts was noted on day 42 in broilers treated with PO mist $(P<0.05)$ relative to groups $\mathrm{C}$ and TO where the values of RBC parameters were comparable. A similar trend was observed in HGB concentration and HCT levels $(P<0.01)$.

The influence of EO mist on leukogram parameters is presented in Table 3. On day 28, monocyte percentage was nearly three times lower in group PO than in group TO $(P<0.01)$ and two and a half times 
lower than in group $C(P<0.05)$. On day 35, a marked increase in lymphocyte counts was noted in broiler chickens treated with TO $(P<0.05)$. This trend was more pronounced in the following week $(P<0.01)$. A reverse trend was observed in the percentage of heterophiles. On day 42 , the percentage of heterophiles was lower in group TO $(P<0.01)$ than in the remaining groups where it did not differ. A higher percentage of lymphocytes and a lower percentage of heterophiles in group TO influenced the $\mathrm{H} / \mathrm{L}$ ratio which was lowest in group TO beginning on day 35. On day 42, the difference between group TO and the remaining groups was statistically confirmed $(P<0.01)$.

Table 2 Effects of essential oil mist on red blood cell parameters in broiler chickens (mean values ${ }^{1}, \mathrm{SEM}$ )

\begin{tabular}{lcccccc}
\hline Parameter & Days & Control & Peppermint oil & Thyme oil & SEM & $P$-value \\
\hline & 28 & 2.36 & 2.39 & 2.34 & 0.037 & $\mathrm{NS}^{2}$ \\
$\mathrm{RBC}^{3}\left(10^{6} / \mu \mathrm{L}\right)$ & 35 & 2.28 & 2.31 & 2.30 & 0.036 & $\mathrm{NS}$ \\
& 42 & $2.36^{\mathrm{b}}$ & $2.57^{\mathrm{a}}$ & $2.38^{\mathrm{b}}$ & 0.062 & 0.015 \\
& 28 & 8.48 & 8.52 & 8.39 & 0.166 & $\mathrm{NS}$ \\
$\mathrm{HGB}(\mathrm{g} / \mathrm{dL})$ & 35 & 8.16 & 8.18 & 8.14 & 0.140 & $\mathrm{NS}$ \\
& 42 & $8.03^{\mathrm{B}}$ & $8.86^{\mathrm{A}}$ & $8.06^{\mathrm{B}}$ & 0.603 & 0.009 \\
& 28 & 32.19 & 32.42 & 31.68 & 0.564 & $\mathrm{NS}$ \\
$\mathrm{HCT}(\%)$ & 35 & 32.03 & 32.12 & 30.29 & 0.469 & $\mathrm{NS}$ \\
& 42 & $29.71^{\mathrm{B}}$ & $32.52^{\mathrm{A}}$ & $29.59^{\mathrm{B}}$ & 0.710 & 0.009
\end{tabular}

\footnotetext{
${ }^{\text {A-B }}$ Mean values within a row having different superscripts differ at level of $P<0.01$

${ }^{a-b}$ Mean values within a row having different superscripts differ at level of $P<0.05$

${ }^{1} \mathrm{~N}=16 ;{ }^{2} \mathrm{NS}-P>0.05$

${ }^{3} \mathrm{RBC}$ - red blood cells; HGB - haemoglobin concentration; HCT - haematocrit levels
}

Table 3 Effects of essential oil mist on leukogram in broiler chickens (mean values ${ }^{1}$, SEM)

\begin{tabular}{lcccccc}
\hline Parameter & Days & Control & Peppermint oil & Thyme oil & SEM & $P$-value \\
\hline \multirow{3}{*}{ Heterophils (\%) } & 28 & 41.10 & 40.11 & 42.60 & 1.807 & $\mathrm{NS}^{2}$ \\
& 35 & 35.60 & 34.77 & 33.30 & 1.994 & $\mathrm{NS}$ \\
& 42 & $43.90^{\mathrm{A}}$ & $45.20^{\mathrm{A}}$ & $33.10^{\mathrm{B}}$ & 2.729 & 0.009 \\
Basophils (\%) & 28 & 4.40 & 3.33 & 3.80 & 1.597 & $\mathrm{NS}$ \\
& 35 & 3.70 & 4.22 & 3.00 & 0.500 & $\mathrm{NS}$ \\
& 42 & 4.00 & 2.80 & 2.90 & 0.514 & $\mathrm{NS}$ \\
Eosinophils (\%) & 28 & 1.70 & 1.11 & 1.40 & 0.229 & $\mathrm{NS}$ \\
& 35 & 1.20 & 1.22 & 0.90 & 0.251 & $\mathrm{NS}$ \\
& 42 & 1.70 & 2.10 & 1.40 & 0.317 & $\mathrm{NS}$ \\
Lymphocytes (\%) & 28 & 50.20 & 54.44 & 49.30 & 1.971 & $\mathrm{NS}$ \\
& 35 & $55.40^{\mathrm{b}}$ & $55.78^{\mathrm{b}}$ & $59.50^{\mathrm{a}}$ & 2.270 & 0.031 \\
& 42 & $49.10^{\mathrm{B}}$ & $48.00^{\mathrm{B}}$ & $60.60^{\mathrm{A}}$ & 2.858 & 0.009 \\
Monocytes (\%) & 28 & $2.60^{\mathrm{a}}$ & $1.00^{\mathrm{Bb}}$ & $2.90^{\mathrm{A}}$ & 0.391 & 0.009 \\
& 35 & 4.10 & 4.00 & 3.30 & 0.435 & $\mathrm{NS}$ \\
& 42 & 1.40 & 1.90 & 2.00 & 0.362 & $\mathrm{NS}$ \\
H/L ${ }^{3}$ ratio & 28 & 0.87 & 0.76 & 0.88 & 0.068 & $\mathrm{NS}$ \\
& 35 & 0.67 & 0.64 & 0.59 & 0.063 & $\mathrm{NS}$ \\
& 42 & $1.00^{\mathrm{A}}$ & $1.02^{\mathrm{A}}$ & $0.57^{\mathrm{B}}$ & 0.106 & 0.004
\end{tabular}

\footnotetext{
${ }^{\mathrm{A}-\mathrm{B}}$ Mean values within a row having different superscripts differ at level of $P<0.01$

${ }^{a-b}$ Mean values within a row having different superscripts differ at level of $P<0.05$

${ }^{1} \mathrm{~N}=16 ;{ }^{2} \mathrm{NS}-\mathrm{P}>0.05 ;{ }^{3} \mathrm{H} / \mathrm{L}-$ heterophiles to lymphocytes
} 
The effects of EO mist on serum protein and protein fractions are presented in Table 4. The mean values of serum total protein did not differ $(P<0.05)$ between groups in all test series. On day 28 , the percentage of albumins was higher $(P<0.001)$ in group $P O$ than in the remaining groups. Differences in the albumin ratio were not found in older birds. In weeks 4 and 5 , the percentage of alpha1-globulins was considerably higher $(28 d-P<0.001 ; 35 d-P<0.01)$ in the group of birds exposed to PO mist. However, on day 42 the percentage of alpha1-globulins decreased in all groups, and it was $(P<0.05)$ higher in group TO than in group $C$. The percentages of alpha2-globulins and beta-globulins were similar in all groups at each stage of the growth cycle. On day 28, the percentage of gamma-globulins was higher in group PO than in groups $C$ and TO $(P<0.01)$. An increase in the gamma-globulin fraction was noted in group TO on day 35 , and it was sustained until day 42, with a significant difference between the experimental groups $(P<0.05)$. The concentration of C-reactive protein was similar in all groups, and it ranged from $0.14 \mathrm{mg} / \mathrm{L}$ (TO; $42 \mathrm{~d}$ ) to 0.23 (PO; $35 \mathrm{~d}$ ). Despite the above, greater fluctuations in CRP levels were observed in experimental groups on different days, and a marked decrease in CRP concentration was noted in both experimental groups on day 42.

Table 4 Effects of essential oil mist on serum protein and protein fractions in broiler chickens (mean values ${ }^{1}$, SEM)

\begin{tabular}{|c|c|c|c|c|c|c|}
\hline Parameter & Days & Control & Peppermint oil & Thyme oil & SEM & $P$-value \\
\hline \multirow{3}{*}{ Total protein (g/dL) } & 28 & 2.65 & 2.63 & 2.84 & 0.064 & $\mathrm{NS}^{2}$ \\
\hline & 35 & 3.08 & 3.10 & 3.01 & 0.069 & NS \\
\hline & 42 & 3.06 & 3.05 & 3.09 & 0.101 & NS \\
\hline \multirow{3}{*}{ Albumins (\%) } & 28 & $68.28^{Z}$ & $71.46^{Y}$ & $69.21^{z}$ & 0.841 & 0.0001 \\
\hline & 35 & 59.55 & 58.37 & 59.22 & 0.824 & NS \\
\hline & 42 & 55.06 & 55.28 & 52.77 & 0.972 & NS \\
\hline \multirow{3}{*}{ Alpha1-globulins (\%) } & 28 & $5.26^{z}$ & $8.76^{\curlyvee}$ & $5.50^{z}$ & 0.358 & 0.0001 \\
\hline & 35 & $6.46^{\mathrm{B}}$ & $7.88^{\mathrm{A}}$ & $6.43^{\mathrm{B}}$ & 0.275 & 0.009 \\
\hline & 42 & $5.02^{\mathrm{a}}$ & $5.92^{\mathrm{ab}}$ & $6.23^{\mathrm{b}}$ & 0.324 & 0.044 \\
\hline \multirow{3}{*}{ Alpha2-globulins (\%) } & 28 & 8.56 & 8.50 & 8.03 & 0.369 & NS \\
\hline & 35 & 10.46 & 9.79 & 9.74 & 0.582 & NS \\
\hline & 42 & 10.00 & 9.90 & 9.79 & 0.385 & NS \\
\hline \multirow{3}{*}{ Beta-globulins (\%) } & 28 & 7.56 & 7.22 & 6.47 & 0.357 & NS \\
\hline & 35 & 8.19 & 8.21 & 8.30 & 0.301 & NS \\
\hline & 42 & 7.60 & 8.67 & 8.15 & 0.314 & NS \\
\hline \multirow{3}{*}{ Gamma-globulins (\%) } & 28 & $10.35^{\mathrm{B}}$ & $14.09^{A}$ & $10.80^{\mathrm{B}}$ & 0.615 & 0.002 \\
\hline & 35 & 14.44 & 15.75 & 16.30 & 0.658 & NS \\
\hline & 42 & $22.32^{\mathrm{ab}}$ & $20.24^{b}$ & $23.05^{\mathrm{a}}$ & 0.829 & 0.020 \\
\hline \multirow{3}{*}{$\mathrm{CRP}^{3}(\mathrm{mg} / \mathrm{L})$} & 28 & 0.17 & 0.22 & 0.20 & 0.021 & NS \\
\hline & 35 & 0.18 & 0.23 & 0.19 & 0.023 & NS \\
\hline & 42 & 0.18 & 0.15 & 0.14 & 0.022 & NS \\
\hline
\end{tabular}

${ }^{Y-Z}$ Mean values within a row having different superscripts differ at level of $P<0.001$

${ }^{A-B}$ Mean values within a row having different superscripts differ at level of $P<0.01$

${ }^{a-b}$ Mean values within a row having different superscripts differ at level of $P<0.05$

${ }^{1} \mathrm{~N}=16 ;{ }^{2} \mathrm{NS}-\mathrm{P}>0.05$

${ }^{3} \mathrm{CRP}-\mathrm{C}$-reactive protein

Lymphoid organ parameters calculated in successive weeks of the growth cycle and the ratio of immune organ weight to BW are presented in Table 5. The weights of the BF, thymus and spleen on days 7 , $14,21,28,35$ and 42 are shown in Figure 1. The BF index did not differ $(P>0.05)$ between groups or 
experimental weeks. However, the lowest value of the BF index was noted in the control group (Table 5). The weight of BF increased in all groups between weeks 1 and 5, and it decreased suddenly after day 35, in particular in the control group (Figure 1a). The average thymus index was also lowest in the control group, and the difference between the control group and experimental groups was statistically confirmed $(P<0.01)$. Despite the above, the thymus index decreased in group TO in the last week of the experiment (Table 5). Thymus weight ceased to increase on day 35 in group TO, but it continued to increase until the end of the experiment in the remaining groups, in particular in group PO (Figure 1b). Spleen weight in broilers exposed to TO mist increased after day 28 (Figure 1c). The ratio of spleen weight to BW (index) was also higher in group TO, in particular on the last day of the experiment $(P<0.001)$.

Table 5 Relative weights of lymphoid organs in broiler chickens (mean values ${ }^{1}$, SEM)

\begin{tabular}{lcccccc}
\hline Index $^{3}$ & Days & Control & Peppermint oil & Thyme oil & SEM & $P$-value \\
\hline \multirow{4}{*}{ Bursa of Fabricius } & 7 & 1.34 & 1.70 & 1.97 & 0.140 & $\mathrm{NS}^{2}$ \\
& 21 & 1.91 & 2.12 & 2.16 & 0.152 & $\mathrm{NS}$ \\
& 42 & 1.22 & 1.47 & 1.70 & 0.126 & $\mathrm{NS}$ \\
& $1-42$ & 1.92 & 2.04 & 2.07 & 0.101 & $\mathrm{NS}$ \\
Thymus & 7 & 3.79 & 4.75 & 4.89 & 0.224 & $\mathrm{NS}$ \\
& 21 & 4.49 & 4.85 & 5.48 & 0.346 & $\mathrm{NS}$ \\
& 42 & 4.11 & 4.19 & 3.75 & 0.347 & $\mathrm{NS}$ \\
& $1-42$ & $4.17^{\mathrm{B}}$ & $4.79^{\mathrm{A}}$ & $4.74^{\mathrm{A}}$ & 0.141 & 0.004 \\
Spleen & 7 & $0.57^{\mathrm{b}}$ & $0.73^{\mathrm{ab}}$ & $0.88^{\mathrm{a}}$ & 0.022 & 0.011 \\
& 21 & 0.88 & 0.84 & 0.90 & 0.051 & $\mathrm{NS}$ \\
& 42 & $1.14^{\mathrm{Z}}$ & $1.05^{\mathrm{Z}}$ & $1.89^{\mathrm{Y}}$ & 0.107 & 0.0001 \\
& $1-42$ & $0.91^{\mathrm{B}}$ & $0.89^{\mathrm{B}}$ & $1.08^{\mathrm{A}}$ & 0.047 & 0.007 \\
\hline
\end{tabular}

${ }^{Y-Z}$ Mean values within a row having different superscripts differ at level of $P<0.001$

A-B Mean values within a row having different superscripts differ at level of $P<0.01$

${ }^{a-b}$ Mean values within a row having different superscripts differ at level of $P<0.05$

${ }^{1} \mathrm{~N}=8 ;{ }^{2} \mathrm{NS}-P>0.05$

${ }^{3}$ Organ weight $(\mathrm{g}) \times 1000 /$ body weight $(\mathrm{g})$

\section{Discussion}

Our results demonstrate that the use of EO mist does not adversely affect broiler growth performance, and that PO mist can increase BW and WG in broiler chickens. The reason for greater WG in group PO could be a higher level of environmental cleanliness and, in consequence, lower susceptibility to infections because PO exerts bactericidal effects on environmental microorganisms (Witkowska \& Sowińska, 2013; Witkowska et al., 2016). Due to its potent antioxidant properties, PO helps maintain the structural integrity of immune system cells and protects cell membranes against free radical-induced oxidation, thus enhancing the immune response (Arab-Ameri et al., 2016; Awaad et al., 2016).

This is the first study to investigate poultry responses to EO mist. Other authors reported that dietary supplementation with EO improves the growth performance of broilers (Saleh et al., 2018). In a study by Arab-Ameri et al. (2016), broilers whose diets were supplemented with peppermint powder had higher BW on day 42 of the experiment. Awaad et al. (2016) also observed that feed supplementation with a blend of peppermint and eucalyptus EO improved the immune status and performance of broiler chickens infected with the Newcastle disease virus, increased final BW, decreased final FCR and total mortality. Al-Kassie (2010) analysed the performance of broilers whose diets were supplemented with different doses of dry peppermint and observed higher weekly WG and lower FCR in chicks fed a lower (0.5\%) than a higher (1.5\%) peppermint dose. Ocak et al. (2008) demonstrated that neither peppermint nor thyme leaves affected the growth performance of birds, but peppermint leaves were more likely to promote growth than thyme in the early stages of life. In our study, final WG and weight at slaughter were also lower in broiler chickens misted with TO. The results reported by other authors were less consistent. Toghyani et al. (2010b) observed 


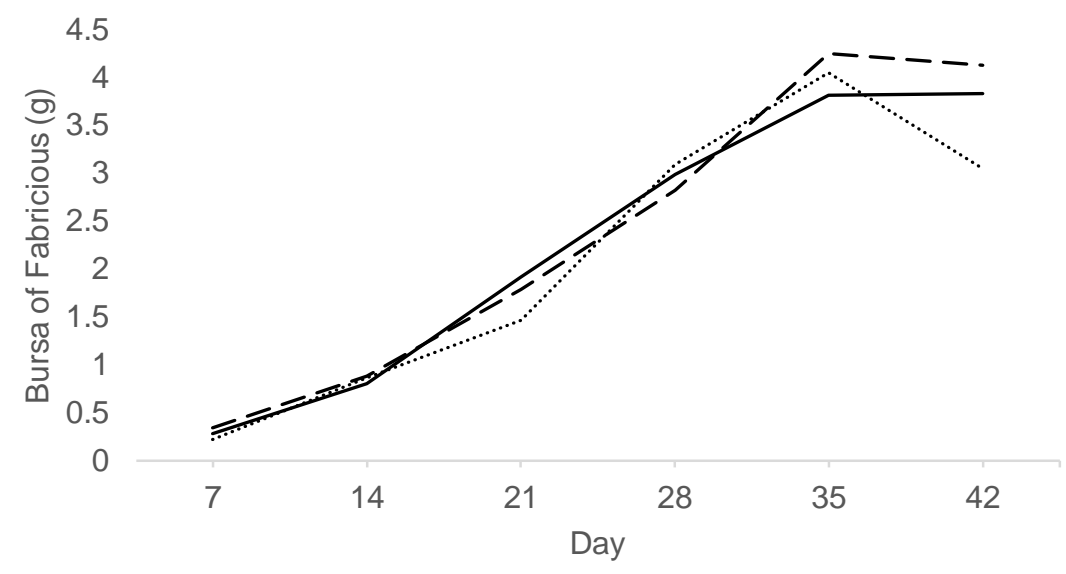

(a) $\mathrm{C} \longrightarrow \mathrm{PO}---\mathrm{TO}$

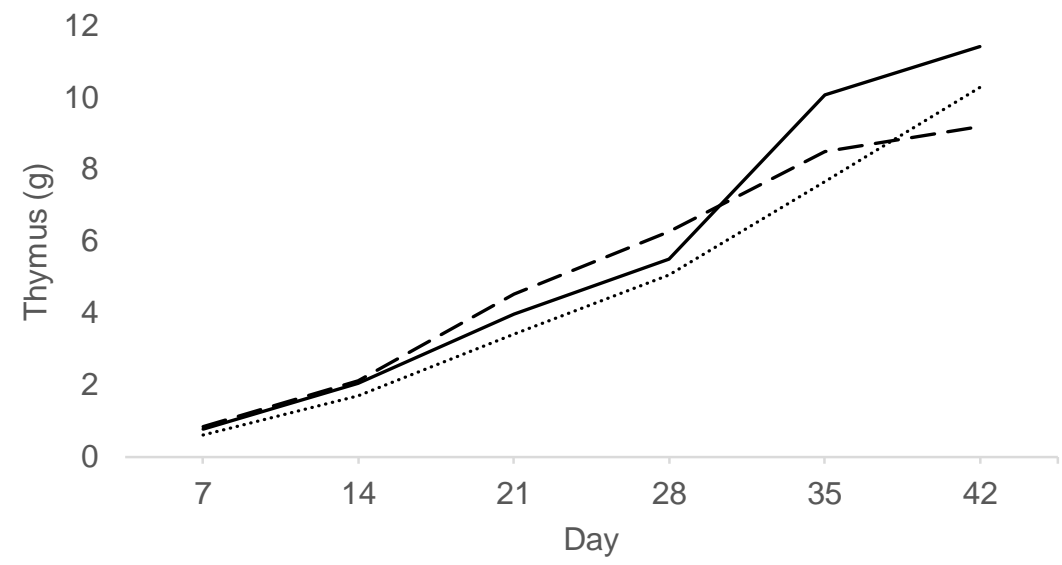

(b)
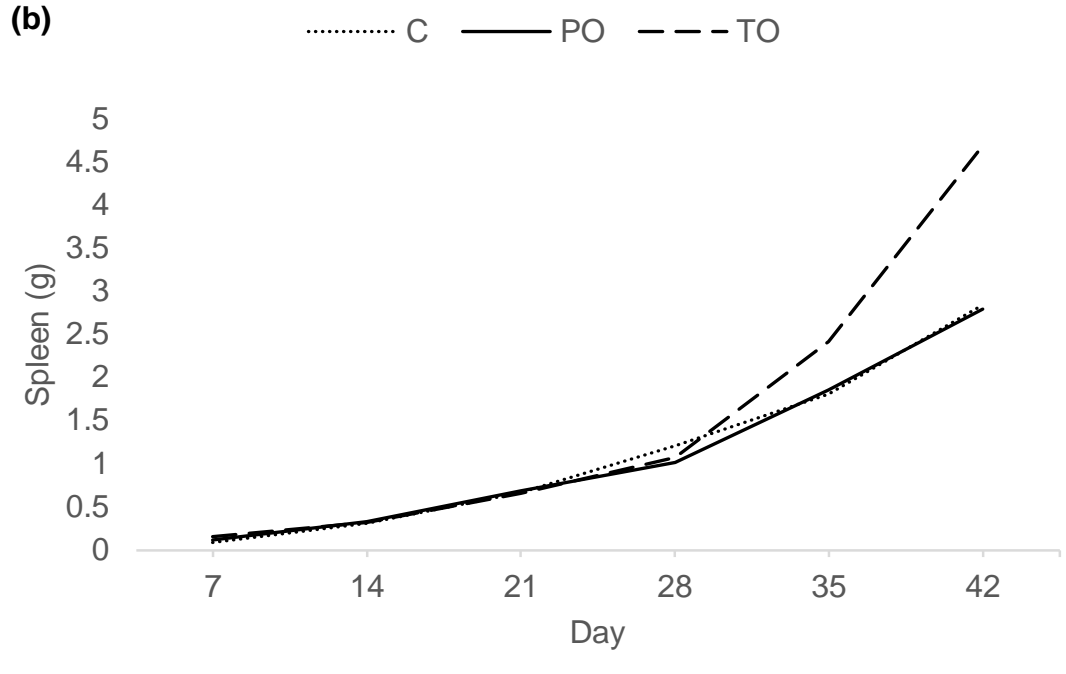

(c) $\mathrm{C} \longrightarrow \mathrm{PO}--\mathrm{TO}$

Figure 1 Effect of essential oil mist on the weights of the bursa of Fabricius (a), thymus (b) and spleen (c) in weeks 1 to 6 $\mathrm{C}=$ control; $\mathrm{PO}=$ peppermint oil; $\mathrm{TO}=$ thyme oil

with a mixture of thymol and cinnamaldehyde than in control birds. Bento et al. (2013) observed an increase in BW and lower mortality in broilers fed wheat-based diets supplemented with thymol and cinnamaldehyde 
that the growth-promoting effects of thyme were comparable to those of an antibiotic (flavophospholipol). Tiihonen et al. (2010) reported significantly higher average WG in broilers whose diets were supplemented over a period of 42 days. Hashemipour et al. (2013) demonstrated that terpenes such as thymol and carvacrol enhanced WG and feed efficiency and reduced feed intake. In our study, FCR values did not differ significantly across groups. However, feed intake was highest and FCR was least desirable in group TO $(P>0.05)$. Toghyani et al. (2010b) observed that feed intake in broilers was not markedly influenced by EO treatments, but FCR values were higher in birds administered thyme than in birds treated with antibiotics.

Cross et al. (2007) reported an almost 10\% increase in feed consumption in birds whose diets were supplemented with TO. However, in contrast to our study, the cited authors observed higher WG in broilers receiving TO. In a study by Ahmed et al. (2016), FCR values were lower in broilers administered PO than peppermint leaves. In our experiment, FCR values were lower in chickens exposed to PO compared with those exposed to TO. In a study by Arab-Ameri et al. (2016), birds whose diets were supplemented with peppermint were characterised by lower FCR values than birds administered flavomycin or control group birds. Other studies demonstrated that the growth performance of broilers was not affected by diets containing oregano EO (Botsoglou et al., 2012). Hernàndez et al. (2004) observed that a blend of oils (including PO) or herbal extracts (including thyme) had no influence on performance parameters, but they improved the nutrient digestibility of broiler feeds. Mitch et al. (2004) demonstrated that a blend of thyme and oregano EO with antibacterial properties was effective in controlling the proliferation of Clostridium perfringens in the gut and faeces of broilers, and could be useful in the treatment of necrotic enteritis (NE). Jerzsele et al. (2012) confirmed that broilers infected with C. perfringens and treated with EO (ginger oil and carvacrol) were more resistant to NE. Treated birds were also characterised by higher WG and lower histopathological lesion scores in the digestive tract. In a study by Tiihonen et al. (2010), EO supplementation exerted a positive effect on intestinal microbiota and enhanced growth performance. In contrast, Cross et al. (2007) did not observe positive effects of herbal and EO supplements on gut microbiota, but reported the highest growth performance in birds administered TO. Their results could be attributed to the stimulatory effect of EO on endogenous secretions, which explains the highest concentration of sialic acid in birds administered TO.

The mean values of RBC parameters at slaughter were statistically higher in the group of broiler chickens exposed to PO mist in comparison with the remaining groups. This could have resulted from the strong antioxidant properties of PO, because peppermint is a rich source of polyphenolic compounds (Toghyani et al., 2010a; Asadi et al., 2017). Hence, increasing RBC counts in broilers fed diet with herbs could be due to lower lipid peroxide levels in RBC membranes. Reduced lipid oxidation in erythrocytes may contribute to the strengthening of cell membrane stability and decreasing erythrocyte susceptibility to hemolysis, and it may have a positive effect on haematopoiesis (Toghyani et al., 2010a; Bardzardi et al., 2014). Al-Kassie (2010) did not observe significant differences in the haematological parameters of broilers fed peppermint relative to the control group. The effects of EO mist on blood parameters have been scarcely researched, but some authors demonstrated that herbal dietary supplements may improve blood cell parameters. Al-Kassie (2009) found that diets supplemented with thyme and cinnamon oil extracts significantly increased RBC counts, HCT, and HGB values in broilers in comparison with the control group. In our study, exposure to TO mist did not affect RBC, HGB or HCT in broilers. Toghyani et al. (2010b) also observed that diets containing thyme failed to induce significant changes in the haematological parameters of broilers, including RBC counts, HCT, and HGB values. In a study by Hashemipour et al. (2013), dietary supplementation with thymol and carvacrol did not affect RBC parameters. They observed a linear decrease in the values of the $\mathrm{H} / \mathrm{L}$ ratio in birds fed thymol and carvacrol. In our study, lymphocyte percentages increased and heterophile percentages decreased in group TO, which resulted in the lowest $\mathrm{H} / \mathrm{L}$ ratio in that group. According to Bedanova et al. (2007), diets containing thymol and carvacrol decreased the $\mathrm{H} / \mathrm{L}$ ratio and reduced stress in broilers. Al-Kassie (2010) observed the lowest H/L ratio in the group supplemented with a minimum dose of peppermint. The author attributed the above result to nutritional stress or other stressors that increase the $\mathrm{H} / \mathrm{L}$ ratio. Stress factors could stimulate the adrenal gland to produce hormones such as oestrogen, which could influence lymphatic cell counts and increase the H/L ratio. In our study, exposure to $\mathrm{PO}$ did not influence the $\mathrm{H} / \mathrm{L}$ ratio which remained similar to that noted in the control group. Toghyani et al. (2010b) also observed that the H/L ratio did not differ significantly across treatments. They demonstrated that the supplementation of broiler diets with thyme powder did not affect protein concentration or the albumin to globulin ratio. In our study, EO mist had no effect on total protein concentration. Despite the above, a marked increase in the percentages of albumins, alpha1-globulins and gamma-globulins was noted in group PO on day 28. Ahmed et al. (2016) reported an increase in total plasma globulin levels in response to dietary supplementation with PO. Arab-Ameri et al. (2016) observed that the addition of peppermint powder to broiler diets increased total $\mathrm{Ig}$, IgM and IgG titres against sheep RBC. According to Ahmed et al. (2016), dietary supplementation with both PO and an antibiotic growth promoter induced a minor 
improvement in plasma immunity indicators in chicks. In our study, gamma-globulin levels increased in group TO on day 35, and this trend was most significantly pronounced on day 42. In group TO, the levels of monocytes (which transform into macrophages after migration from blood to peripheral tissues) were highest $(P<0.01)$ on day 28. These results indicate that TO aromatherapy can stimulate humoral and cell-mediated immunity in chickens. The active compounds of volatile oils influence phagocytic activity in the blood serum, and they can increase nitric oxide levels. Moreover, the phagocytic activity of macrophages can also be enhanced. Macrophages perform a variety of functions other than phagocytosis. They act as secretory cells, produce nitric oxide that kills intracellular microorganisms, and secrete many different proteins such as lysosomal enzymes and cytokines that play a key role in regulating immunity (Awaad et al., 2016). Hashemipour et al. (2013) demonstrated that continuous application of thymol and carvacrol had the potential to enhance cellular and humoral immune responses. The authors reported a primary $(7 \mathrm{~d}$ after injection) response against the sheep RBC antigen and IgG; an enhanced secondary (14 d after injection) response and an increase in IgG in birds fed diets containing thymol and carvacrol were also observed.

The BF is a primary lymphoid organ which plays an important role in B lymphocyte differentiation and immune responses in poultry (Cazaban et al., 2015). In our study, the BF/BW ratio in each group was within the reference range (Cazaban et. al., 2015). No significant differences in the BF index were found between groups. However, it should be noted that the BF index and the weight of BF were lowest in the control group. Gamma-globulin levels were also lowest in the control group. Awaad et al. (2016) analysed and scored histomorphological changes in the immune organs, and observed lymphocytic hyperplasia and lymphoblast activation in broiler chickens fed diets supplemented with peppermint and eucalyptus oils. The authors cited above concluded that the administration of these volatile oils has a potent immunomodulatory effect and evokes immune responses in chickens. Ahmed et al. (2016) observed the highest values of the BF index in the group supplemented with PO. In the work of Toghyani et al. (2010b), thyme did not affect the weights of lymphoid organs. Hashemipour et al. (2013) also demonstrated that lymphoid organ parameters were not affected in broilers fed thymol and carvacrol, but in groups administered the highest dose of the supplement, the relative weights of the spleen, BF and thymus were higher than in the control group and in groups receiving lower doses. Similar results were reported by Rahimi et al. (2011). In our experiment, the thymus index was lowest in the control group, and the difference between control and experimental groups was statistically significant. The spleen index was higher in group TO, in particular on the last day of the experiment. In this group, FCR was highest and final BW was lowest, possibly because immunostimulation exerted adverse effects on the growth performance of broilers since more nutrients were repartitioned to synthesize antibodies and develop the immune organs, thereby decreasing the pool of nutrients available for growth. The pleiotropic effects of genes associated with immune responsiveness can also be the reason for negative correlations between BW and antibody responses (Rahimi et al., 2011). Stressful conditions can promote changes and atrophy of immune organs (Kusandi \& Djulardi, 2011; Cazaban et al., 2015) because growth inhibition increases corticosterone secretion (Kusandi \& Djulardi, 2011). However, high values of immune organ indices are not always indicative of good health. Hashemipour et al. (2013) noted that excessive growth of lymphoid organs could be indicative of infection and higher mortality in broiler chickens. In our study, the exposure to EO mist did not deteriorate broiler health; mortality cases were sporadic and similar in all groups.

It should be noted that this study analysed the influence of EO mainly on the respiratory tract; therefore, their mechanism of action differed from that noted in the digestive tract. Essential oils are volatile and easily inhaled via the respiratory tract and lungs, which facilitates their distribution in the bloodstream. The respiratory tract and dermal absorption are the most immediate exposure pathways (Djilani \& Dicko, 2012). Inhaled drugs directly reach the target organ; therefore, the administered dose can be lower than in systemic delivery (oral or injection), which reduces the number and severity of adverse side effects (Rau, 2005). Essential oils can also affect mucosa-associated lymphoid tissue (MALT) responsible for immunostimulation, which indirectly improves performance and the health status of broiler chickens. The antimicrobial properties of EO mist improve hygiene standards (Bakutis et al., 2011; Witkowska \& Sowińska, 2013; Witkowska et al., 2016) and contribute to higher performance. The aroma of selected EO mist could also influence chicken behaviour and feed intake. The dose of EO also affects growth performance, blood parameters, and immune organs (Toghyani et al., 2010b; Hashemipour et al., 2013; Arab-Ameri et al., 2016). According to Cross et al. (2007), herbs and EO have different effects on broiler performance, mainly due to differences in their terpene composition. The quality of broiler diets and environmental conditions are important factors in the assessment of poultry response to terpenes.

\section{Conclusions}

Our results demonstrate that PO and TO mists do not exert adverse effects on broiler health, and that PO could increase the final BW of birds and RBC parameters. The analysed blood and lymphoid organ 
parameters indicate that EO could positively affect the immune system of broilers. Higher values of gammaglobulin concentrations as well as the weight and growth indices of lymphoid organs were noted in experimental groups. The effectiveness of EO mists as health and growth promoters is not well documented in the literature. Further research is needed to determine the immune response mechanisms in broilers exposed to different doses of EO mist in practical terms.

\section{Authors' Contributions}

DW designed the experiment and drafted the manuscript. All authors conducted the experiment, analysed and interpreted the results of the study. All authors approved the final version of the manuscript.

\section{Conflict of Interest Declaration}

There are no conflicts of interest.

\section{References Done}

Abudabos, A.M. \& Alyemni, A., 2013. Effects of the essential oil blend CRINA ${ }^{\circledR}$ Poultry in feed on broiler performance and gut microbiology. Italian J. Anim. Sci. 12 (4), 513-517.

Ahmed, A.M.H., El-Sanhoury, M.H.S. \& Mostafa, M.M.E., 2016. Effect of peppermint extracts inclusion in broiler chick diet on chick performance, plasma constituents, carcass traits and some microbial populations, enzymatic activity and histological aspects of small intestine. Asian J. Anim. Vet. Adv. 11, 441-451.

Al-Kassie, G.A.M., 2009. Influence of two plant extracts derived from thyme and cinnamon on broiler performance. Pak. Vet. J. 29, 169-173.

Al-Kassie, G.A.M., 2010. The role of peppermint (Mentha piperita) on performance in broiler diets. Agric. Biol. J. N. Am. 1, 1009-1013.

Arab Ameri, S., Samadi, F., Dastar, B. \& Zerehdaran, S., 2016. Effect of peppermint (Mentha piperita) powder on immune response of broiler chickens in heat stress. Iran. J. Appl. Anim. Sci. 6, 435-445.

Asadi, N., Husseini, S.D., Tohidian, M.T., Abdali, N., Mimandipoure, A., Rafieian-Kopaei, M. \& Bahmani, M., 2017. Performance of broilers supplemented with peppermint (Mentha piperita L.) powder. J. Evid. Based Complementary Altern. Med. 22 (4), 703-706.

Awaad, M.H.H., Abdel-Alim, G.A., Sayed Kawkab, K.S.S., Ahmed, A., Nada, A.A., Metwalli, A.S.Z. \& Alkhalaf, A.N., 2010. Immunostimulant effects of essential oils of peppermint and eucalyptus in chickens. Pak. Vet. J. 30, 61-66.

Awaad, M.H.H., Afify, M.A.A., Zoulfekar, S.A., Mohammed, F.F., Elmenawy, M.A. \& Hafez, H.M., 2016. Modulating effect of peppermint and eucalyptus essential oils on VND infected chickens. Pak. Vet. J. 36, 350-355.

Bakutis, B., Baliukoniene, V. \& Mickienè, R., 2011. The use of essential oils to improve of environment quality in poultry houses. Proceeding in 15th ISAH Congress, Vienna, Austria. 2, 643-645.

Bardzardi, M., Ghazanfari, S. \& Sharifi, S.D., 2014. Growth performance, carcass characteristics, antibody titer and blood parameters in broiler chickens fed dietary myrtle (Myrtus communis) essential oil as an alternative to antibiotic growth promoter. Poult. Sci. J. 5 (2), 37-49.

Bedanova, I., Voslarova, E., Chloupek, P., Pistekova, V., Suchy, P., Blahova, J., Dobsikova, R. \& Vecere, V., 2007. Stress in broilers resulting from shackling. Poult. Sci. 86, 1065-1069.

Bento, M.H.L., Ouwehand, A.C., Tiihonen, K., Lahtinen, S., Nurminen, P., Saarinen, M.T., Schulze, H., Mygind, T. \& Fischer, J., 2013. Essential oils and their use in animal feeds for monogastric animals - Effects on feed quality, gut microbiota, growth performance and food safety: a review. Vet. Med. (Praha). 58, 449-458.

Botsoglou, N.A., Florou-Paneri, P., Christaki, E., Fletouris, D.J. \& Spais, A.B., 2012. Effect of dietary oregano essential oil on performance of chickens and on iron-induced lipid oxidation of breast, thigh and abdominal fat tissues. Br. Poult. Sci. 43, 223-230.

Brenesa, A. \& Rourab, E., 2010. Essential oils in poultry nutrition: main effects and modes of action. Anim. Feed Sci. Technol. 158, 1-14.

Cazaban, C., Masferrer, N.M., Pascual, R.D., Espadamala, M.N., Costa, T. \& Gardin, Y., 2015. Proposed bursa of Fabricius weight to body weight ratio standard in commercial broilers. Poult. Sci. 95, 2088-2093.

Clark, P., Boardman, W.S.J. \& Raidal, S., 2009. Atlas of clinical avian hematology. John Wiley \& Sons Ltd., United Kingdom.

Cross, D.E., Mcdevitt, R.M., Hillman, K. \& Acamovic, T., 2007. The effect of herbs and their associated essential oils on performance, dietary digestibility and gut microflora in chickens from 7 to 28 days of age. Br. Poult. Sci. 48, 496-506.

Darabighane, B., Gheshlagh, F., Navidshad, B., Mahdavi, A., Zarei, A. \& Nahashon, S., 2017. Effects of peppermint (Mentha piperita) and Aloe vera (Aloe barbadensis) on ileum microflora population and growth performance of broiler chickens in comparison with antibiotic growth promoter. Iran. J. Appl. Anim. Sci. 7 (1), 101-108.

Djilani, A. \& Dicko, A., 2012. The therapeutic benefits of essential oils, nutrition, wellbeing and health. In: Nutrition, Well-Being and Health. Bouayed, J. (ed). Tech, Rijeka, Croatia. pp. 156-178.

Ghazanfari, S., Mohammadi, Z. \& Adib Moradi, M., 2015. Effects of coriander essential oil on the performance, blood characteristics, intestinal microbiota and histological of broilers. Braz. J. Poult. Sci. 17, 419-426.

Hashemipour, H., Kermanshahi, H., Golian, A. \& Veldkamp, T., 2013. Effect of thymol and carvacrol feed supplementation on performance, antioxidant enzyme activities, fatty acid composition, digestive enzyme activities, and immune response in broiler chickens. Poult. Sci. 92, 2059-2069. 
Hernàndez, F., Madrid, J., García, V., Orengo, J. \& Megías, M.D., 2004. Influence of two plant extracts on broiler performance, digestibility, and digestive organ size. Poult. Sci. 83, 169-174.

Ibrahim, M., Verma, R. \& Garcia-Contreras, L., 2015. Inhalation drug delivery devices: technology update. Med. Devices (Auckl). 8, 131-139.

Inouye, S., Abe, S., Yamaguchi, H. \& Asakura, M., 2003. Comparative study of antimicrobial and cytotoxic effects of selected essential oils by gaseous and solution contacts. Int. J. Aromather. 13, 33-41.

Jerzsele, A., Szeker, K., Csizinszky, R., Gere, E., Jakab, C., Mallo, J.J. \& Galfi, P., 2012. Efficacy of protected sodium butyrate, a protected blend of essential oils, their combination, and Bacillus amyloliquefaciens spore suspension against artificially induced necrotic enteritis in broilers. Poult. Sci. 91, 837-843.

Juergens, U.R., Dethlefsen, U., Steinkamp, G., Gillissen, A., Repges, R. \& Vetter, H., 2003. Anti-inflammatory activity of 1.8-cineol (eucalyptol) in bronchial asthma: a double-blind placebo-controlled trial. Respir. Med. 97, 250-256.

Kalemba, D., 1998. Antibacterial and antifungal properties of essential oils. Post. Mikrobiol. 38, 185-203 (in Polish).

Kusandi, E. \& Djulardi, A., 2011. Physiological dynamic of broiler at various environmental temperatures. Int. J. Poult. Sci. 10, 19-22.

Lutomski, J. \& Kędzia, B., 2000. The estimation of volatile oils and their compounds in respect to the antiinflammatory and immunostimulatory effects. Post. Fitoter. 1, 32-35 (Polish).

Mitsch, P., Zitterl-Eglseer, K., Köhler, B., Gabler, C., Losa, R. \& Zimpernik, I., 2004. The effect of two different blends of essential oil components on the proliferation of Clostridium perfringens in the intestines of broiler chickens. Poult. Sci. 83, 669-675.

Mituniewicz, T., Sowińska, J., Wójcik, A., Iwańczuk-Czernik, K., Witkowska, D. \& Banaś, J., 2008. Effect of disinfectants on physicochemical parameters of litter, microbiological quality of hen house air, health status and performance of broiler chickens. Pol. J. Environ. Stud. 17, 745-750.

Ocak, N., Erener, G., Burak Ak, F., Sungu, M., Altop, A. \& Ozmen, A., 2008. Performance of broilers fed diets supplemented with dry peppermint (Mentha piperita L.) or thyme (Thymus vulgaris L.) leaves as growth promoter source. Czech J. Anim. Sci. 53, 169-175.

Placha, I., Takacova, J., Ryzner, M., Cobanova, K., Laukova, A., Strompfova, V., Venglovska, K. \& Faix, S., 2014. Effect of thyme essential oil and selenium on intestine integrity and antioxidant status of broilers. Br. Poult. Sci. 1, 105-114.

Pournazari, M., Qotbi, A.A.A., Seidavi, A.R. \& Corazzin, M., 2017. Prebiotics, probiotics and thyme (Thymus vulgaris) for broilers: performance, carcass traits and blood variables. Rev. Colom. de Cienc. Pecua. 30 (1), 3-10.

Rahimi, S., Teymouri Zadeh, Z., Karimi Torshizi, M.A., Omidbaigi, R. \& Rokni, H., 2011. Effect of the three herbal extracts on growth performance, immune system, blood factors and intestinal selected bacterial population in broiler chickens. J. Agr. Sci. Technol. 13, 527-539.

Rau, J.L., 2005. The inhalation of drugs: advantages and problems. Respir. Care. 50, 367-82.

Sadlon, A.E. \& Lamson, D.W., 2010. Immune-modifying and antimicrobial effects of eucalyptus oil and simple inhalation devices. Altern. Med. Rev. 15, 33-47.

Saleh, A.A., Ebeid, T.A. \& Abudabos, A.M., 2018. Effect of dietary phytogenics (herbal mixture) supplementation on growth performance, nutrient utilization, antioxidative properties and immune response in broilers. Environmental Sci. Pollution Res. 25, 14606-14613.

Tiihonen, K., Kettunen, H., Bento, M.H.L., Saarinen, M., Lahtinen, S., Ouwehand, A.C., Schulze, H. \& Rautonen, N., 2010. The effect of feeding essential oils on broiler performance and gut microbiota. Br. Poult. Sci. 51, 381-392.

Toghyani, M., Toghyani, M., Gheisari, A., Ghalamkari, G. \& Mohammadrezaei, M., 2010a. Growth performance, serum biochemistry and blood hematology of broiler chicks fed different levels of black seed (Nigella sativa) and peppermint (Mentha piperita). Livest. Sci. 129, 173-178.

Toghyani, M., Tohidi, M., Gheisari, A.A. \& Tabeidian, S.A., 2010b. Performance, immunity, serum biochemical and hematological parameters in broiler chicks fed dietary thyme as alternative for an antibiotic growth promoter. Afr. J. Biotechnol. 9, 6819-6825.

Wade, M.R., Manwar, S.J., Kuralkar, S.V., Waghmare, S.P., Ingle, V.C. \& Hajare, S.W., 2018. Effect of thyme essential oil on performance of broiler chicken. J. Entomol. Zool. Stud. 6 (3), 25-28.

Witkowska, D. \& Sowińska, J., 2013. The effectiveness of peppermint and thyme essential oil mist in reducing bacterial contamination in broiler houses. Poult. Sci. 92, 2834-2843.

Witkowska, D. \& Sowińska, J., 2017. Identification of microbial and gaseous contaminants in poultry farms and developing methods for contamination prevention at the source. In: Poultry Science. Manafi, M. (ed). Tech, Rijeka, Croatia. pp. 51-72.

Witkowska, D., Szarek, J., Iwańczuk-Czernik, K., Sowińska, J., Mituniewicz, T., Wójcik, A. \& Babińska, I., 2007. Effect of disinfecting litter on rearing performance and results of blood indices and internal organs of broiler chickens. Med. Weter. 63, 1115-1119.

Witkowska, D., Sowińska, J., Żebrowska, J.P. \& Mituniewicz, E., 2016. The antifungal properties of peppermint and thyme essential oils misted in broiler houses. Braz. J. Poult. Sci. 18, 629-638. 